\title{
WORD OF WELCOME
}

Mr Chairman, Dr. Vollmar, ladies and gentlemen!

It is indeed a pleasure on behalf of the National Parks Board of Trustees to welcome all the delegates to the symposium which coincides with the 50th anniversary of the National Parks Board.

I think it human after 50 years to think back and to give a summary of the years past. When we talk about Nature Conservation, it is natural to make a summary of what has been done not only in the Republic of South Africa (RSA) but in the whole of southern Africa. Therefore, knowledgeable persons have been approached to evaluate critically the position of Nature Conservation in southern Africa. In some instances, certain countries could not be represented due to political upheaval.

On behalf of the National Parks Board of Trustees I extend a very hearty word of welcome to each and every one and to those who have come from afar to take this opportunity of not only noting what has been done in the Republic of South Africa, but also look with a critical eye on what they think should be done. I would like to welcome representatives of the National Parks Board of Trustees and similarly the welcome is extended to representatives of Lesotho, Rhodesia, Swaziland, Bophutatswana, the Ciskei, Gazankulu, Kwa-Zulu, Lebowa, Quaqua, the Swazi Territorial authority, the Republic of the Transkei, the Venda, the Provincial Administrations of the RSA, the Universities of Pretoria and Stellenbosch, the South African Nature Foundation, SATOUR, the National Zoological Gardens, the National Botanical Gardens, different Government Departments and last, but not least, the Wildlife Society of Southern Africa.

You will permit me to mention one name i.e. Dr Fritz Vollmar and his good lady. Dr Vollmar is the Director General of the World Wildlife Fund (WWF) employed in finding the necessary funds for the establishment of new National Parks all over the world. We are very pleased to have them here.

I sincerely hope, ladies and gentlemen, that you will leave our boundaries (after completion of our proposed programme) with optimism and enthusiasm as far as Nature Conservation is concerned. We appreciate your presence at this, our 50th anniversary. We shall try our best to do what is still to be done (albeit a long-time programme) and I would emphasise the fact that we are to learn considerably from this symposium on your account - the mere fact of your presence here being testimonial of our common idealism.

The Hon S G J van Niekerk

Chairman

National Parks Board of Trustees 